\title{
Risk Perception in the Construction Industry: Differences Between Italian and Migrant Workers Before and After a Targeted Training Intervention
}

NEW SOLUTIONS: A Journal of Environmental and Occupational Health Policy $0(0) \mathrm{I}-7$

(C) The Author(s) 2021

Article reuse guidelines: sagepub.com/journals-permissions DOI: |0.1 |77/I04829| I21998364 journals.sagepub.com/home/new (S)AGE

\author{
Federico Ricci', Giulia Bravo² (D, Alberto Modenese', \\ Fabrizio De Pasquale ${ }^{3}$, Davide Ferrari ${ }^{3}$ and Fabriziomaria Gobba'
}

\begin{abstract}
We developed a visual tool to assess risk perception for a sample of male construction workers (forty Italian and twentyeight immigrant workers), just before and after a sixteen-hour training course. The questionnaire included photographs of real construction sites, and workers were instructed to select pictograms representing the occupational risks present in each photograph. Points were awarded for correctly identifying any risks that were present, and points were deducted for failing to identify risks that were present or identifying risks that were not present. We found: $(I)$ Before the course, risk perception was significantly lower in immigrants compared to Italians $(p<.00 \mathrm{I})$; $(2)$ risk perception improved significantly $(p<.00 \mathrm{I})$ among all workers tested; and (3) after the training, the difference in risk perception between Italians and immigrants was no longer statistically significant $(p=.1086)$. Although the sample size was relatively small, the results suggest that the training is effective and may reduce the degree to which cultural and linguistic barriers hinder risk perception. Moreover, the use of images and pictograms instead of words to evaluate risk perception could also be applied to nonconstruction workplaces.
\end{abstract}

\section{Keywords}

risk perception, construction, Italian and immigrant workers, safety training, effectiveness

\section{Introduction}

The high risk of occupational injuries in the construction industry is well known. In 2017, more than 20 percent of all fatal injuries at work in Europe occurred in this sector. ${ }^{1}$ Figures show that construction in many countries outside Europe is as dangerous as in Europe or even more so. Due to the inherent danger of this industry, an accurate perception of risk is important so that workers can protect themselves. In the present study, we assume that risk perception is the result of subjective considerations on the probability of suffering damage to health, regarding a source of risk, and the consequent emotions that it arouses. ${ }^{2}$

Familiarity with a task has been found to diminish the risk perception associated with frequently performed activities. $^{3}$

Age is another factor to be considered, especially for immigrant workers. Among younger workers, there is double the rate of injuries, including those with serious consequences, compared to adult workers. Therefore, as well as training, it is necessary to define strategies to reduce the excess injury rate among younger workers, often precariously employed.

Employers should be more aware of the limitations of school-based safety education, and a more integrated and evidence-based approach should be developed involving schools and workplaces. ${ }^{4}$ In addition, workers may expose themselves to risks due to the desire to be efficient. ${ }^{5}$ There is evidence that young immigrant construction workers are less likely to have received adequate training: according to one study, the average

\footnotetext{
'University of Modena and Reggio Emilia, Modena, Italy

${ }^{2}$ University of Udine, Udine, Italy

${ }^{3}$ Local Health Unit Company, Modena, Italy

Corresponding Author:

Giulia Bravo, University of Udine, via Colugna 50, Udine 33100, Italy.

Email: giulia.bravo@uniud.it
} 
training time is only one hour, with only 24 percent reporting that they received written training materials, and those with a poorer level of English receiving less training. ${ }^{6}$

Mistakes in risk perception can result from inattention or lack of awareness on the part of workers. ${ }^{7}$ According to the Dynamic Safety Model, ${ }^{8}$ worker motivation to reach high levels of productivity pushes workers "close to the limit" in terms of exposure to hazards." The ability to identify risks can improve safety in the construction industry. ${ }^{10}$

A recent study aimed at evaluating effective interventions to improve knowledge and risk perception in adolescents indicated that knowledge influences behavioral intention through attitude and self-efficacy. ${ }^{11}$ People actively learn in the environment in which they are placed, and action facilitates learning more than passive observation alone. ${ }^{12}$ When safety culture, defined as shared standards and values within an organization, is weak, a higher rate of injuries, possibly related to a reduced risk perception, can be expected. ${ }^{13}$ There is evidence that the injury rate in construction among Italian workers decreases with increased experience and familiarity with the work organization, and with better interaction with colleagues. ${ }^{14}$ These effects are more detectable among Italian workers than among immigrants because, on average, Italians have longer tenure with construction companies, and they tend to receive less dangerous assignments. ${ }^{15}$ On the other hand, it is more difficult for immigrant workers to integrate with colleagues and to adapt to the work organization due to linguistic and cultural barriers that limit their access to information on the risks associated with their work. ${ }^{16}$

A significant number of immigrants work in industrialized countries. They are often employed as unskilled workers ${ }^{17}$ and engaged in high-risk tasks with an inadequate level of training, possibly due to a lack of understanding of the local language. ${ }^{18}$ Training the correct risk perception is necessary, since, according to the perspective of control theory applied to safety at work, when an individual (or a group) feels the discrepancy that there is no expected level of safety, this should determine a commitment to change practices to achieve the desired improvement. ${ }^{19}$ However, it is not enough because factors external to the individual, such as those indicated in the following paragraphs, could lead to unsafe behavior, even in the presence of correct risk perception. $^{20}$

It should also be considered that few immigrant workers are unionized, and this is associated with a greater tendency to take risks, in the absence of legal protection. They often have jobs in the shadow economy, with limited access to the necessary health and safety information and resources. ${ }^{21}$ The situation is particularly serious for immigrants who have entered the country illegally, as they fear losing their jobs or being deported. $^{22}$ The protection of rights, for example in occupational health, is often impeded by fear and stigma, and fear can also hinder the collective mobilization of undocumented immigrants. ${ }^{23}$ Furthermore, the need to support one's family financially may lead to risk acceptance. In other cases, malnutrition and difficult living conditions may lead to poor concentration and increase the risk of accidents and injuries. ${ }^{22}$ Probably these circumstances may be the main reasons why immigrants expose themselves to dangerous conditions, despite knowing the risks they face.

We believe that this can help to explain immigrant workers' risk exposure. Thus, it is necessary to provide training and to assess its effectiveness in order to reduce work injuries. $^{24-26}$

In particular, a necessary but not the only aim of training must be to improve risk identification. ${ }^{27}$

Unfortunately, trainers often fail to apply adult learning principles. When used, such methods increase learning, retention, and adherence to safety requirements. ${ }^{28}$

Italian Legislative Decree $81 / 08$ is the key Italian law regulating the prevention and promotion of occupational health and safety. The law requires sixteen hours of training before employment begins to promote professional competence and safety.

The purpose of the study is to understand to what degree the mandatory sixteen-hour training course provided by the Modena Vocational School for Construction Workers (https://www.scuolaedilemo dena.it/notizie/progetto-16-ore.html) contributes to improving risk perception. The study used an ad hoc questionnaire in which photographs of hazardous construction situations were presented. Trainees were asked to respond by choosing the pictograms which depicted the types of occupational risk present in the photographs.

In particular, we tested the following hypotheses:

H1: at a baseline level, the perception of occupational risk by Italian workers is higher than for immigrant workers;

$\mathrm{H} 2$ : a sixteen-hour training course can change/improve the risk perception of the whole group (Italian and immigrant construction workers);

H3: the change/improvement in risk perception for such a training course is similar in Italian and immigrant construction workers.

To reduce the impact of culture and language fluency on the evaluation, we decided to use an innovative imagebased tool. 


\section{Materials and Methods}

\section{Participants}

The study involved sixty-eight newly hired male construction workers (forty Italian and twenty-eight immigrant workers). All attended a sixteen-hour training course on general and specific occupational risks in construction work held at the "Modena Vocational School for Construction Workers." The group considered was part of a larger sample of construction workers $(n=527)$, involved in a study in various regions of Italy aimed at developing and validating a tool to investigate possible differences in the perception and representation of risk between workers belonging to different ethnic groups. ${ }^{17}$

\section{Method and Procedure}

Risk perception was evaluated using a tool comprising a set of fourteen pictures (see Figure 1 for an example) representing real workplace situations, giving rise to different types and levels of occupational risk.

The subjects were asked to recognize the existence and type of risk by selecting one or more of six pictograms representing different types of risks/injuries that could occur in the photographed situations. For each photograph, the participants were asked to mark one or more pictograms with a cross according to the risk (s) identified in the depicted situation ("What event can happen in this working situation?"). The test was performed immediately before, and after, the sixteen-hour training course. The workers were given a set of fourteen sheets of paper, each reproducing one of the pictures and six pictograms. The fourteen pictures were then shown

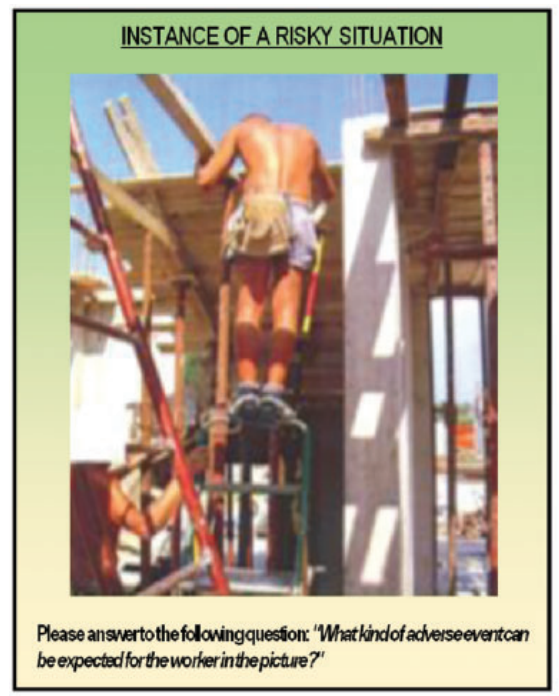

to the group of subjects in a slide show at regular intervals for around fifteen seconds per photograph.

The "correct" type and level of occupational risk occurring in the situations represented in the pictures was estimated based on the evaluation of a panel of occupational health and safety experts.

The answers to each picture were evaluated as follows:

- nonexistent risk(s) incorrectly identified or existing risk(s) not identified: -1 for each

- existing risk(s) correctly identified: +1 for each

Accordingly, for each subject, we calculated a "risk score" by adding (or subtracting) the values obtained across the whole sequence of images, with a higher score when participants identified risks correctly.

\section{Statistical Analysis}

The characteristics of the groups involved were compared using current descriptive statistical techniques. The association between categorical variables was then assessed using chi-square or Fisher's exact test; for quantitative variables, the differences between the two groups of workers were assessed using the Wilcoxon MannWhitney test (Kolmogorov-Smirnov test was used to evaluate the normal distribution). Analyses were performed using R i386 3.1.0 and $\alpha=0.05$ was chosen as the significance level.

\section{Results}

The age of Italian and immigrant workers was not significantly different $(p=.4202)$, although Italians showed

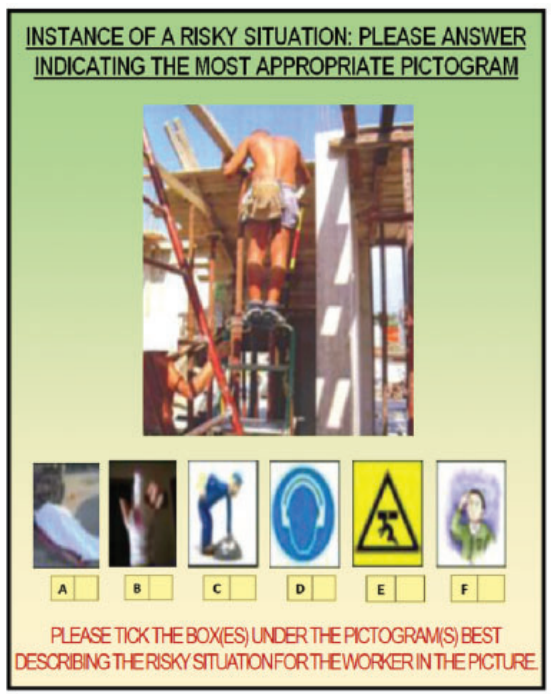

Figure I. Example of item included in the tool of risk perception evaluation. 
a median age of five years lower than immigrants and even though the oldest of the nonnative workers was twenty years younger than the Italian oldest (Table 1).

The main socioeconomic characteristics are presented in Table 2. Regarding educational level, roughly more than half of the whole sample had a medium or high level of education. The level was even higher in immigrants: In about 70 percent of cases, the education level was medium/high, compared to 50 percent for Italians, even if the difference is not significant. In both groups, about half the sample had never worked in construction or had less than one year of experience, whereas 29 percent of immigrants compared to 7.5 percent of Italians had worked in construction for six to ten years, while a quarter of the Italians had worked more than ten years, compared to 7 percent for immigrants; in any case, once again the differences between the groups are not significant. Finally, and not surprisingly, only 21 percent of immigrant workers held a position with a higher level of qualification than general construction worker (e.g., foreman, team leader, skilled worker), compared to 35 percent of Italians, but the difference is not significant.

Moving on to the results of the evaluation of risk perception, the results are presented in Table 3 and show that before the course, the risk perception of immigrant workers was significantly lower compared to Italian workers $(p<.001)$; according to these results, Hypothesis H1 was correct.

It seems that, in the complete group of Italian and immigrant construction workers, the training was successful in increasing risk perception $(p<.001)$ from -6 (median before training) to +6 (median after training), and therefore the data also supports Hypothesis H2.

Lastly, the "risk score" was slightly higher for Italians, but the gap between the groups was largely reduced and did not differ significantly $(p=.1086)$. Therefore, Hypothesis H3 is shown to be false because the training was able to cause a greater increase in risk

Table I. Mean, Median and Minimum and Maximum Values of Age in All Workers and in the Two Groups.

\begin{tabular}{llll}
\hline Age & $\begin{array}{c}\text { All workers } \\
(n=68)\end{array}$ & $\begin{array}{c}\text { Italian workers } \\
(n=40)\end{array}$ & \multicolumn{1}{c}{$\begin{array}{c}\text { Migrant workers } \\
(n=28)\end{array}$} \\
\hline Mean $\pm S D$ & \multicolumn{1}{c}{$(n=90 \pm 9.54$} & $28.98 \pm 11.31$ & $28.79 \pm 6.69$ \\
Median (IQR) & $27.00(13.50)$ & $23.50(18.00)$ & $28.00(11.00)$ \\
Min-max & $17-62$ & $17-62$ & $18-42$ \\
\hline
\end{tabular}

Note. $\mathrm{SD}=$ standard deviation; $\mathrm{IQR}=$ interquartile range.

Table 2. Main Socioeconomical Characteristics of the Examined Groups of Workers.

\begin{tabular}{|c|c|c|c|c|}
\hline & $\begin{array}{l}\text { All workers } \\
\quad(n=68)\end{array}$ & $\begin{array}{l}\text { Italian workers } \\
\quad(n=40)\end{array}$ & $\begin{array}{l}\text { Migrant worker } \\
\quad(n=28)\end{array}$ & \\
\hline & \multicolumn{3}{|c|}{$n(\%)$} & $p$ value \\
\hline \multicolumn{5}{|l|}{ Education } \\
\hline None & I (I.47) & I (2.50) & $0(0.00)$ & .4431 \\
\hline Low education (primary/lower secondary level) & $28(4|| 8)$. & $19(47.50)$ & $9(32.10)$ & \\
\hline Medium education & $37(54.4 I)$ & $19(47.50)$ & $18(64.20)$ & \\
\hline High education (university level) & $2(2.94)$ & I (2.50) & I (3.70) & \\
\hline \multicolumn{5}{|l|}{ Previous experience in construction } \\
\hline No previously engaged & $23(33.82)$ & $15(37.50)$ & $8(28.60)$ & .1203 \\
\hline$<$ I year & $12(17.65)$ & $6(15.00)$ & $6(2 I .4 I)$ & \\
\hline $1-3$ years & $4(5.88)$ & $2(5.00)$ & $2(7.13)$ & \\
\hline $4-5$ years & $6(8.82)$ & $4(10.00)$ & $2(7.13)$ & \\
\hline $6-10$ years & II (16.18) & $3(7.50)$ & $8(28.60)$ & \\
\hline$>10$ years & $12(17.65)$ & $10(25.00)$ & $2(7.13)$ & \\
\hline \multicolumn{5}{|l|}{ Job position } \\
\hline Foreman & $3(4.4 I)$ & $3(7.50)$ & $0(0.00)$ & .5472 \\
\hline Team leader & $5(7.35)$ & $3(7.50)$ & $2(7.15)$ & \\
\hline Specialized workman & $12(17.65)$ & $8(20.00)$ & $4(14.30)$ & \\
\hline Workman & $26(38.24)$ & $12(30.00)$ & $14(50.00)$ & \\
\hline Unemployed & $7(10.29)$ & $5(12.50)$ & $2(7.15)$ & \\
\hline Other & $15(22.06)$ & $9(22.50)$ & $6(21.40)$ & \\
\hline
\end{tabular}


Table 3. Risk Perception of Workers Before and After the Training Course.

\begin{tabular}{|c|c|c|c|c|c|}
\hline \multirow[b]{2}{*}{ Risk perception } & \multicolumn{2}{|c|}{ Italian workers $(n=40)$} & \multicolumn{2}{|c|}{ Migrant workers $(n=28)$} & \multirow[b]{2}{*}{$p$ value } \\
\hline & Mean $\pm S D$ & Median (min; max) & Mean $\pm S D$ & Median (min; max) & \\
\hline Before training course & $-3.67 \pm 03.42$ & $-4(-I I ; 4)$ & $-8.68 \pm 4.34$ & $-9(-1 \mid ;-6)$ & $<.001$ \\
\hline After training course & $8.25 \pm 1.96$ & $8(6 ; 10)$ & $5.05 \pm 1.58$ & $5(3 ; 8)$ & .1086 \\
\hline
\end{tabular}

Note. $\mathrm{SD}=$ standard deviation.

perception in immigrant workers than in the Italian group.

\section{Discussion}

The application of a new method, based on visual stimuli representing real workplace situations of which the workers have some direct knowledge, is promising in detecting risk perception. As described, the tool comprises a set of fourteen sheets, each with an image depicting real workplaces and tasks. Six pictograms, representing different types of injury risks that may occur in the depicted situation, were easily understood by the workers. The "risk score" was calculated by adding the correctly identified existing risk(s) and subtracting the number of incorrectly identified nonexistent risk(s) or unidentified existing risk(s). Immigrant workers exhibited poorer risk perception before the training (Table 3). Attendance at the training course resulted in an improvement in risk perception in the whole sample, including both Italian and immigrant workers (Table 3).

After the training, the difference in risk score performance between Italian and immigrant workers was reduced (risk scores were still slightly higher among Italian workers). This observation shows that this training helped immigrants to overcome disadvantages in risk perception.

Our results are consistent with previous research, ${ }^{20,29,30}$ suggesting that the use of workplace photographs to measure risk perception contributes to overcoming language barriers and to improving understanding as demonstrated by the greater increase in the immigrants' risk perception compared to the Italian workers (Table 3).

Classroom discussion of workplace pictures allowed us to explain which practices were safe and unsafe and how to improve unsafe practices. ${ }^{31}$ The use of pictures becomes fundamental when laborers have limited language proficiency. Furthermore, the use of images relating to known and easy-to-understand situations makes the teaching material more interesting. ${ }^{32}$

So, the use of visual training materials contributes to overcoming linguistic and cultural barriers, to obtaining better risk perception, and to the practice of safe behaviors. This is fundamental because higher work accident rates are documented for immigrant workers. ${ }^{33}$

\section{Conclusion}

In this paper, we present a newly developed tool specifically aimed at evaluating the perception of occupational risk, based on the use of a set of pictures depicting real construction sites, and pictograms representing the occupational risks aimed at overcoming cultural and linguistic barriers.

We evaluated risk perception using a "risk score" based on the occupational risks in the pictures, with a higher score when participants correctly identified the risks. The method was apparently easily understood and well accepted by both Italian and immigrant workers. Testing before the training indicated a lower perception of risk in immigrant construction workers compared to their Italian counterparts. A sixteen-hour training course was able to improve risk perception in all the workers, reducing the differences between the groups.

This study was limited to a relatively small number of workers and needs further confirmation in larger groups. Nevertheless, the results suggest that the method presented here is promising and could be effective in the evaluation of risk perception even in groups of workers who differ in terms of culture and language. A further advantage of the method presented here is that it can be applied to other contexts.

\section{Limitations}

We are fully aware that focusing on the correct perception of risk is necessary but not sufficient to fully evaluate workplace safety. First of all, action should be taken to reduce and eliminate occupational risks. Then, it is necessary to ensure that all workers, including immigrants, can have control over the improvement of working conditions. ${ }^{34}$ No one should have to accept hazards due to a lack of trade union protection or because they are illegally employed. Risk acceptance may vary due to economic, legal, social, ethnic, and cultural forces. While the method presented here provides an easy and useful tool, effective prevention requires comprehensive actions based on the evaluation of all aspects of this complex phenomenon. 


\section{Implications}

The results suggest that this investigation tool developed for construction workers can detect changes in risk perception as a result of training. Furthermore, the photographs of dangerous workplace conditions and pictograms representing different types of risk proved to be useful instruments for interactive training as well as testing learning outcomes.

Further studies are needed for an in-depth assessment of the factors related to risk perception. Our results were clearly affected by the presence of many unexperienced workers, and we would recommend evaluating the following hypotheses: (a) A higher educational level would benefit (immigrant) workers in the learning phase and (b) higher qualifications would facilitate a better baseline performance.

Finally, it would be interesting to examine whether there is a relationship between risk perception, before and after the course, and years living in Italy.

\section{Declaration of Conflicting Interests}

The author(s) declared no potential conflicts of interest with respect to the research, authorship, and/or publication of this article.

\section{Funding}

The author(s) disclosed receipt of the following financial support for the research, authorship, and/or publication of this article: This work was supported by the Regional Environmental Protection Agency of Emilia-Romagna (ARPAE) (project entitled "Percezione e rappresentazione del rischio in edilizia. Studio e analisi di gruppi di lavoratori di diverse nazionalità e culture"; project manager: Fabrizio De Pasquale).

\section{ORCID iD}

Giulia Bravo (D) https://orcid.org/0000-0002-3149-2883

\section{References}

1. Eurostat, https://ec.europa.eu/eurostat/statisticsexplained/index php? title $=$ Accidents_at_work_statistics (accessed 25 February 2020).

2. Rundmo T. Safety climate, attitudes and risk perception in Norsk Hydro. Saf Sci 2000; 34: 47-59.

3. Zimolong BM and Elke G. Occupational health and safety management. In: Salvendy G (ed) Handbook of human factors and ergonomics. 3rd ed. Hoboken, NJ: John Wiley and Sons, 2006, p.1680.

4. Thamrin Y, Pisaniello D and Stewart S. Time trends and predictive factors for safety perceptions among incoming South Australian university students. J Safety Res 2010; 41: 59-63.

5. Zierold KM, Welsh EC and McGeeney TJ. Attitudes of teenagers towards workplace safety training. J Community Health 2012; 37: 1289-1295.
6. O'Connor T, Loomis D, Runyan C, et al. Adequacy of health and safety training among young Latino construction workers. J Occup Environ Med 2005; 47: 272-277.

7. Abdelhamid TS and Everett JG. Identifying root causes of construction accidents. J Constr Eng Manage 2000; 126: 52-60.

8. Rasmussen J. Risk management in a dynamic society: a modelling problem. Saf Sci 1997; 27: 183-213.

9. Mitropoulos P, Abdelhamid TS and Howell GA. Systems model of construction accident causation. J Constr Eng Manage 2005; 131: 816-825.

10. Perlman A, Sacks R and Barak R. Hazard recognition and risk perception in construction. Saf Sci 2014; 64: 22-31.

11. Guerin RJ. Using a modified theory of planned behavior to measure and assess workplace safety and health knowledge, attitude, perceived behavioral control, and intention among middle school students and middle and high school teachers. Doctoral dissertation, University of Cincinnati, $\mathrm{OH}$, USA, 2017.

12. Frese M and Zapf D. Action as the core of work psychology: a German approach. In: HC Triandis, MD Dunnette and LM Hough (eds) Handbook of industrial and organizational psychology. Vol. 4. Palo Alto, CA: Consulting Psychologists Press, 1994, pp.271-340.

13. Hallowell M. Safety risk perception in construction companies in the Pacific Northwest of the USA. Constr Manag Econ 2010; 28: 403-413.

14. Giraudo M, Bena A and Costa G. Migrant workers in Italy: an analysis of injury risk taking into account occupational characteristics and job tenure. BMC Public Health 2017; 17: 351.

15. Quinlan M, Mayhew C and Bohle P. The global expansion of precarious employment, work disorganisation and occupational health: a review of recent research. Int $J$ Health Serv 2001; 31: 335-414.

16. Bender KA, Mridha HA. and Peoples J. Risk compensation for hospital workers. Ind Labor Relat Rev 2006; 59: 226-242.

17. Ricci F, Modenese A, Bravo G, et al. Ethnic background and risk perception in construction workers: development and validation of an exploratory tool. Int J Occup Med Environ Health 2020; 33: 1-10.

18. Guldenmund F, Cleal B and Mearns K. An exploratory study of migrant workers and safety in three European countries. Saf Sci 2013; 52: 92-99.

19. Beus JM, McCord MA and Zohar D. Workplace safety: a review and research synthesis. Organ Psychol Rev 2016; 6: 352-381.

20. Ricci F, Pelosi A, Panari C, et al. Safety value in practice for an effective occupational health and safety training. In: Organization 4.1: the role of values in the organizations of the 21st century ISSWOV 2018 (International Society for the Study of Work and Organizational Values, Budapest, Hungary, (ed I Baumane-Vītolina), Trieste, Italy, 1-4 July 2018, pp.377-387, https://universityts.wixsite.com/ isswov2018/conference-proceedings (accessed 16 February 2021).

21. Riley K, Delp L, Cornelio D, et al. From agricultural fields to urban asphalt: the role of worker education to promote 
California's heat illness prevention standard. New Solut 2012; 22: 297-323.

22. Peiró JM, Nielsen K, Latorre F, et al. Safety training for migrant workers in the construction industry: a systematic review and future research agenda. J Occup Health Psychol 2020; 25: 275-295.

23. Abrego LJ. Legal consciousness of undocumented Latinos: fear and stigma as barriers to claims-making for first- and 1.5- generation immigrants. Law Soc Rev 2011; 45: 337-370.

24. Ricci F, Pelosi A, Panari C, et al. Safety training 4.0: active, collaborative, human-focused practices, to improve health at work. In: Transdisciplinary engineering methods for social innovation of industry 4.0: proceedings of the 25th ISPE Inc. international conference on transdisciplinary engineering, 3-6 July 2018, Vol. 7, p. 310. Amsterdam, Netherlands: IOS Press. http://ebooks.iospress.nl/ISBN/ 978-1-61499-898-3.

25. Ricci F, Chiesi A, Bisio C, et al. Effectiveness of occupational health and safety training: a systematic review with meta-analysis. J Workplace Learn 2016; 28: 355-377.

26. Brahm $F$ and Singer $M$. Is more engaging safety training always better in reducing accidents? Evidence of selfselection from Chilean panel data. J Safety Res 2013; 47: 85-92.

27. Dzeng RJ, Hsueh $\mathrm{HH}$ and Chang RN. 3D game-based training system for hazard identification on construction site. In: 12th International conference on fuzzy systems and knowledge discovery (FSKD), 15-17 August 2015. Zhangjiajie, China, 2015, pp.2453-2458. Piscataway, NJ: IEEE.

28. Wilkins JR. Construction workers' perceptions of health and safety training programmes. Constr Manag Econ 2011; 29: 1017-1026.

29. Burke MJ, Sarpy SA, Smith-Crowe K, et al. Relative effectiveness of worker safety and health training methods. Am J Public Health 2006; 96: 315-324.

30. Robson LS, Stephenson CM, Schulte PA, et al. A systematic review of the effectiveness of occupational health and safety training. Scand J Work Environ Health 2012; 38: 193-208.

31. De Souza RA, Hecker S, De Castro AB, et al. Novel approaches to development, delivery and evaluation of a peer-led occupational safety training for Latino day laborers. New Solut 2012; 22: 387-405.

32. Magner UIE, Glogger I and Renkl A. Which features make illustrations in multimedia learning interesting? Educ Psychol 2016; 36: 1596-1613.

33. Riccò M, Garbarino S and Bragazzi NL. Migrant workers from the eastern-Mediterranean region and occupational injuries: a retrospective database-based analysis from North-Eastern Italy. IJERPH 2019; 16: 673.

34. Weinstock D and Slatin C. Learning to take action: the goals of health and safety training. New Solut 2012; 22: 255-267.

\section{Author Biographies}

Federico Ricci has been an occupational psychologist since 1993. He is an expert in andragogy and a trainer on nontechnical skills in occupational safety. He conducted and published various researches, in particular in the field of risk perception and safety training effectiveness.

Giulia Bravo has many years of experience performing data management and data analyst. She is involved in various public health research projects in the areas of occupational, clinical, and nutritional health.

Alberto Modenese is an occupational physician, post doc researcher at the Chair of Occupational Medicine of the University of Modena and Reggio Emilia (Modena, Italy). $\mathrm{He}$ is currently Secretary of the Scientific Committee "Radiation and Work" of the International Commission of Occupational Health. His main area of research is the study of preventive measures, exposure evaluation methods, and health effects related to nonionizing radiation exposure and to other occupational risk factors in workers.

Fabrizio De Pasquale has been an environmental and workplace prevention technician for about thirty years. $\mathrm{He}$ deals with occupational health and safety for the public health department of the national health service. $\mathrm{He}$ is also a teacher and didactic tutor of the degree course in prevention sciences at the University of Parma, where he also teaches risk perception. Over the past ten years, he has conducted and published various researches, in particular in the field of risk perception and representation.

Davide Ferrari is an occupational physician, director of the Department of Public Health of the Modena Local Health Unit of the Italian National Health Service. He is actively involved in research in various areas of medical prevention and in particular on the occupational exposure and prevention of chemical and carcinogenic risks, on the evaluation of the risk perception in workers, and on the development of more effective preventive interventions.

Fabriziomaria Gobba is director of the Specialization School in Occupational Medicine of the University of Modena and Reggio Emilia (Modena, Italy). He is a member of the National Board of the Italian Society of Occupational Health (SIML), Vice President of the Italian Association of Medical Radioprotection (AIRM), and former Chair of the Scientific Committee "Radiation and Work" of the International Commission of Occupational Health. His main research areas are the occupational risk related to exposure to selected physical, chemical, and biological risk factors in workplaces and the improvement of occupational prevention. 